\title{
Retos actuales y perspectivas del Centro Nacional de Conservación y Registro del Patrimonio Artístico Mueble, INBA
}

\author{
Gabriela Gil Verenzuela
}

a preservación del patrimonio histórico y artístico de México enfrenta hoy grandes desafíos, relacionados con un escenario global que en los últimos años se ha modificado notablemente en las esferas política, económica y social a escala mundial y local. De ahí que las instituciones encargadas de la salvaguardia de nuestro legado cultural deban adaptarse a las nuevas necesidades y exigencias del presente.

La gestión, conservación y restauración del patrimonio artístico mueble e inmueble correspondiente a los siglos XX y XXI de la historia mexicana están a cargo del Instituto Nacional de Bellas Artes (INBA) — fundado en 1946-que, en concordancia con la normatividad nacional e internacional, ha articulado desde sus inicios dos herramientas primordiales para la protección y preservación del patrimonio artístico: el registro y la catalogación. De hecho, para cumplir con estas funciones específicas, en 1963 el INBA creó el Centro Nacional de Conservación de Obra Artística (CNCOA), cuya misión era preservar, registrar, conservar y restaurar tanto los acervos artísticos en custodia de los museos del mismo instituto como la pintura mural contemporánea ubicada en varios recintos arquitectónicos del país. Esta organización modificó y extendió su acción en el año 2007, para convertirse en el Centro Nacional de Conservación y Registro del Patrimonio Artístico Mueble (Cencropam).

Al trabajar directa e indirectamente sobre la materialidad de algunos de los bienes más significativos del patrimonio cultural mexicano, el Cencropam busca asumir entonces la gran responsabilidad de desarrollar intervenciones que preserven y hagan legibles los valores adscritos a dichas obras. La tarea es de tal envergadura que para afrontarla cabalmente ha requerido un grupo de profesionales de distintas especialidades, incluidos los conservadoresrestauradores, quienes se agrupan en talleres enfocados en el tratamiento de obra de caballete, mural, papel, escultura, madera y artes aplicadas, además de una sección dedicada a demandas museográficas como la preparación y el embalaje de las colecciones.

El centro cuenta, asimismo, con un área de resguardo para la preservación del acervo asignado al propio recinto —situado en el Antiguo Colegio Máximo de San Pedro y San Pablo en el Centro Histórico de la Ciudad de Méxicoy un laboratorio de biodeterioro, que coadyuva en iniciativas de naturaleza preventiva y de manejo contra plagas en las distintas colecciones artísticas 


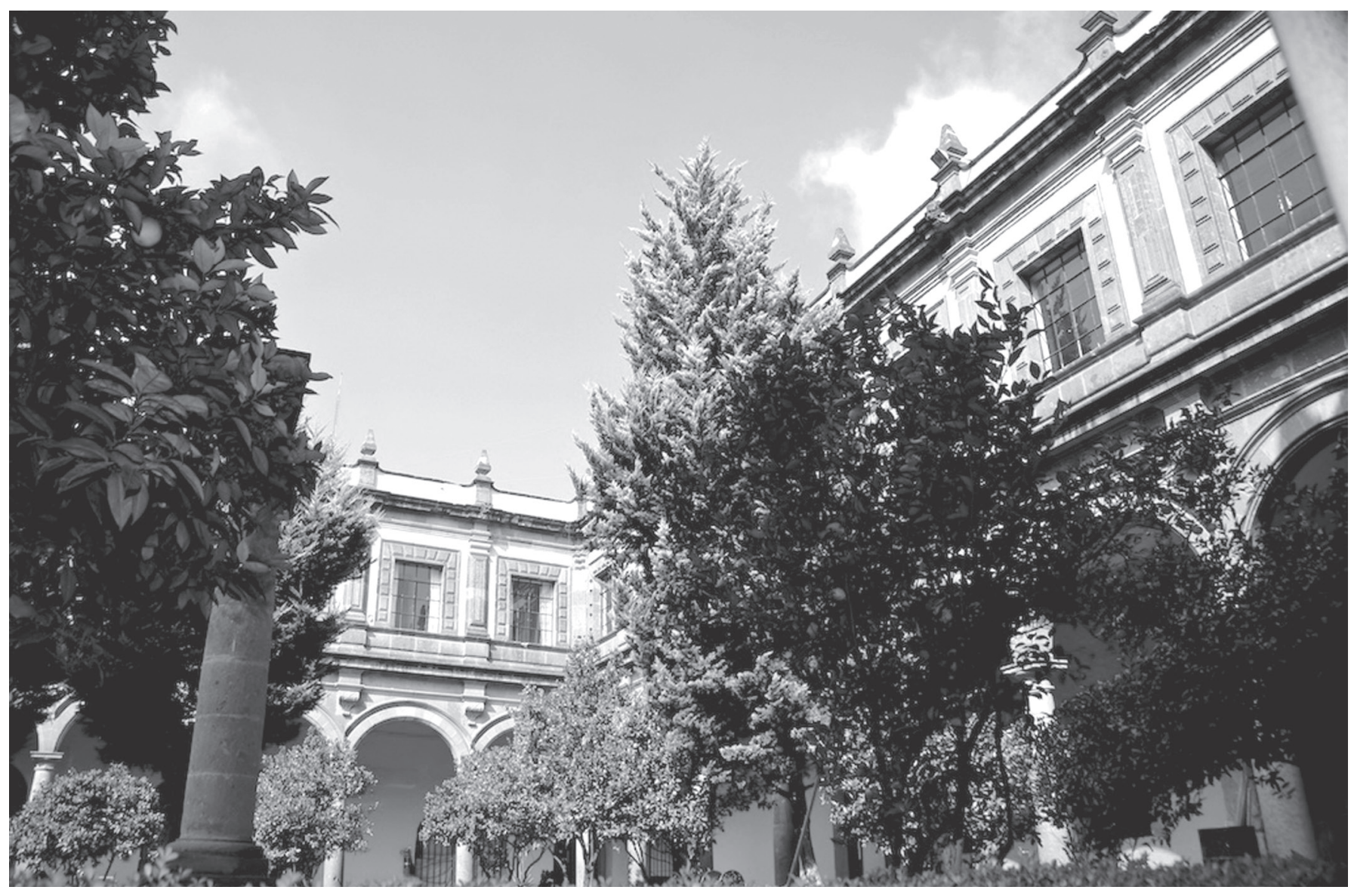

FIGURA 1. Panorámica del patio de la sede del Cencropam (Fotografía José Jasso, 2011; cortesía Cencropam-INBA).

de varios museos de México. Valga subrayar que el desarrollo del trabajo de restauración también busca impulsar los principios generales de la conservación preventiva.

La acción coordinada de diferentes profesionales del Cencropam hace posible, así, profundizar en el significado de los bienes patrimoniales que se intervienen. De manera especial, los restauradores vigilan que sus intervenciones mantengan durante cada proceso el respeto a la materialidad de la obra y a sus valores estéticos, históricos y sociales.

Cabe señalar que la labor de restauro del centro no sólo se centra en acervos de los que el INBA es responsable, sino también se extiende a bienes en manos de coleccionistas particulares y museos privados. En este ámbito general, una estrategia de importancia vital en la actual gestión del Cencropam corresponde a la implantación de un sistema amplio de catalogación del inventario, que hoy se articula a través del Sistema General de Registro de Obra Artística (Sigroa).

Para comprender los retos que enfrenta el Sigroa en la actualidad, vale la pena conocer brevemente la historia del acervo del INBA. Éste se integró, desde la fecha en que se estableció el instituto, a partir de las colecciones de la Secretaría de Educación Pública, de la Antigua Academia de San Carlos, del Palacio de Bellas Artes y del Museo de Arte Popular, así como con todas aquellas obras de arte ubicadas en diferentes recintos que el Estado mexicano consideraba de importancia nacional para la exhibición pública y la difusión estética del patrimonio artístico. Por su origen diverso, no es de extrañar que, desde sus etapas iniciales, el registro del acervo del INBA haya enfrentado dificultades

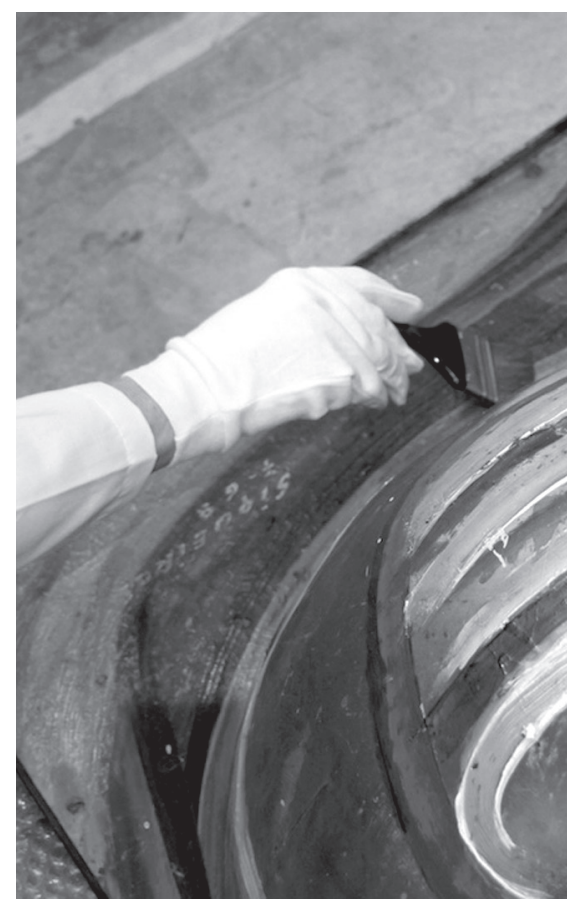

FIGURA 2. Proceso de restauración en taller de pintura de caballete (Fotografía José Jasso, 2011; cortesía Cencropam-INBA). 
en cuanto a la acreditación de la propiedad de las obras. Para solventar tal problemática, en el año de 1994 el propio Estado mexicano solicitó la creación de una base de datos que relacionara de manera puntual las obras bajo responsabilidad del INBA tanto respecto de su tenencia como de los recintos de su ubicación o exhibición.

En virtud de su configuración, el Sigroa cumplió, en su momento, con los fines básicos de inventario: mantenía un registro sobre la ubicación de las obras artísticas en los museos, centros culturales y dependencias gubernamentales de la nación; su base de datos también facilitaba el control del acervo que se encontraba en préstamo temporal o permanente en México y el extranjero. Así, hasta hace poco tiempo, el Sigroa ha servido como el gestor universal para el control del movimiento de la obra artística que posee el INBA, que en la actualidad asciende a 60000 bienes muebles.

Prácticamente desde su fundación, el Cencropam ha sido la instancia encargada del proceso de inventario y registro del patrimonio artístico mueble del instituto. Sin embargo, hoy en día el centro afronta numerosos retos en cuanto al registro: por un lado, es necesario

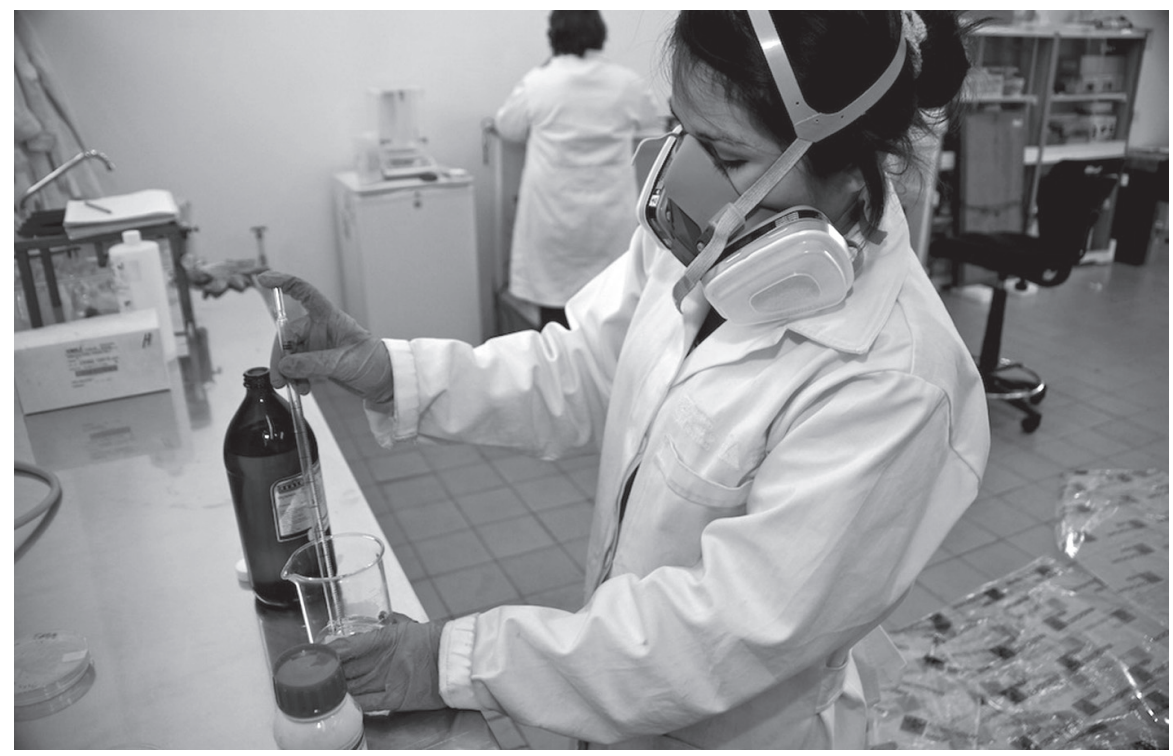

FIGURA 3. Laboratorio de Biodeterioro del Cencropam (Fotografía de José Jasso, 2011; cortesía Cencropam-INBA)

fortalecer, sistematizar y automatizar los procesos de catalogación y control de las obras artísticas muebles; por el otro, es imprescindible vincular de manera eficiente los múltiples esfuerzos realizados al interior de la institución en lo relativo a la preservación, conservación y difusión de patrimonio artístico.

En este sentido, es importante destacar que los acervos y recintos del INBA, que al principio se conformaron de manera errática, no siempre

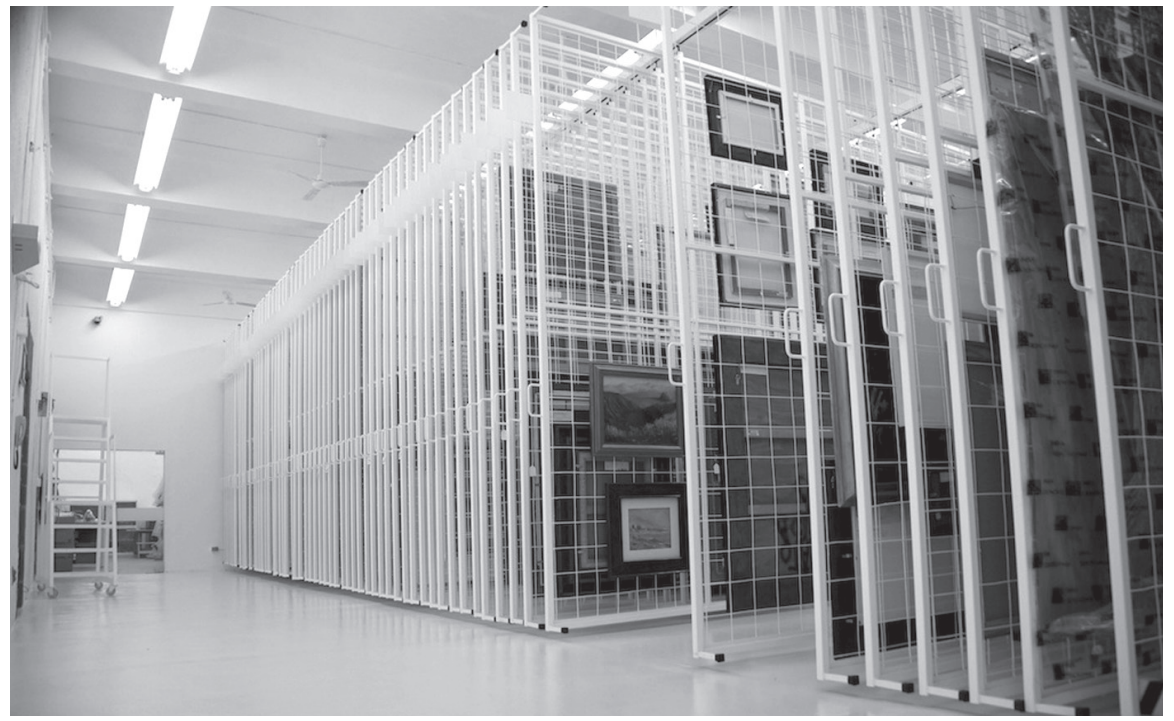

FIGURA 4. Bodega de resguardo del acervo del INBA en el Cencropam (Fotografía José Jasso, 2011; cortesía Cencropam-INBA). han contado con un programa de adquisiciones sistemático que favorezca su protección técnica, jurídica y administrativa, regule la entregarecepción de las obras, o establezca metas a corto, mediano y largo plazos. Ante la falta de un plan maestro de museos nacionales, los espacios de exhibición permanente que integran el patrimonio artístico se han construido de manera circunstancial. Por ello es imperante, además de proceder a la planeación y la ampliación de estos espacios museales, prever la creación de áreas para la conservación de los acervos, así como poner en marcha un amplio sistema de registro y catalogación digital de los pertenecientes al INBA. En este último aspecto, se ha avanzado, en una primera fase, con el Sistema General de Registro de Obra Patrimonio Artístico Mueble (Sigropam).

Desde el punto de vista de la catalogación, el Sigropam trasciende la mera gestión planificada de las colecciones: coadyuva no sólo a una resignificación de la memoria, sino también a la creación de una nueva plataforma del conocimiento. Una de sus metas es llevar las posibilidades del manejo de colecciones a una interconexión y acceso acordes con recientes investigaciones tecno- 
lógicas aplicadas a lo museológico, lo cual permitirá evaluar y complementar la información desarrollada por cada museo en los términos y conceptos asentados por sus propios equipos de profesionales. Reorganizar la catalogación comportará, sin duda, distintas maneras de obtener e ingresar información respecto de temas artísticos. Con esta nueva planificación será posible, partiendo de un tema de interés, promover la interacción con cualquier tipo de público para que pueda reinterpretar o recrear ciertas lecturas del patrimonio artístico.

Una vez estandarizados los contenidos en su ordenamiento interno, el registro y catalogación servirán como fuentes bibliográficas básicas para el manejo y conservación del acervo artístico. Así, una nueva perspectiva de las funciones de gestión de colecciones catalizaría, con el fin de promover una amplia visión cul- tural, las potencialidades de las entidades museísticas del INBA. A largo plazo, las perspectivas apuntan a la integración de una iniciativa de catalogación digital ampliada a todos los bienes y manifestaciones culturales de México.

Con la implantación de una base de datos centralizada, se ha logrado en realidad consolidar las tareas de atención y seguimiento de las colecciones que conforman el acervo del INBA. Afortunadamente, mediante estas acciones y las descritas arriba, que involucran el desarrollo de labores de gran complejidad - debido, entre otros factores, a la vastedad y riqueza del propio acervo, al poder destructivo del tiempo, a la dificultad en la identificación del patrimonio artístico reciente $y$, de manera determinante, a los vacíos jurídicos que restringen la capacidad de acción institucional sobre el patrimonio artístico-, se han logra- do avances sustanciales en cuanto a preservación de la memoria histórica de una parte significativa del legado artístico moderno de México.

Es indiscutible que a la labor del INBA deben sumarse las de la sociedad y de los diferentes órdenes de gobierno para la preservación del patrimonio artístico de la nación. Establecer una vinculación permanente entre el personal del instituto y otras áreas e instituciones con propósitos afines es imprescindible para desarrollar una política patrimonial sustentable. Una máxima prioridad es la incorporación de los distintos actores procedentes del ámbito político, de la esfera administrativo-técnico, del campo académico y la sociedad civil, para concebir una cultura en red, diseñar proyectos que trasciendan el ámbito cultural e instrumentar una política de integración al desarrollo global.

\section{Resumen}

Esta semblanza está dedicada a una de las organizaciones más importantes en la preservación, conservación y difusión del patrimonio artístico en México: el Centro Nacional de Conservación y Registro del Patrimonio Artístico Mueble (Cencropam) del Instituto Nacional de Bellas Artes (INBA). Además de describir brevemente los antecedentes y las funciones actuales del Cencropam-INBA, se analiza su papel significativo en materia de catalogación a través de sus sistemas Sigroa y Sigropam. Un análisis de los alcances logrados y los retos que hoy deben asumirse en el campo del registro e inventario de obra artística conduce a una reflexión sobre las perspectivas de desarrollo de la gestión de colecciones para el INBA y el propio Cencropam.

Palabras clave

Cencropam-INBA, patrimonio artístico, registro, gestión de colecciones

\section{Abstract}

This paper is devoted to one of the most important institutions for the preservation, conservation and dissemination of artistic heritage in Mexico: the Centro Nacional de Conservación y Registro del Patrimonio Artístico Mueble (Cencropam) at the Instituto Nacional de Bellas Artes (INBA). The paper describes Cencropam's background and its current functions, as well as the substantial role of this organization in registering artistic works through the General Systems for Registration of Artistic Works (Sigroa and Sigropam). On the basis of the analysis on the achievements and challenges that the inventory of artistic works faces nowadays, this paper proposes new development perspectives on collection management for both the INBA and Cencropam.

\section{Keywords}

Cencropam-INBA, artistic heritage, registry, collection management. 